\title{
Tratamento do efluente de uma caixa separadora água e óleo: potencial de reuso do efluente em um posto de gasolina
}

\author{
Treatment of effluent from a water and oil separator box: potential of reuse of effluent in a gas
} station

Tratamiento de efluentes de una caja separadora de agua y aceite: potencial de reutilización de efluentes em uma estación de gas

\section{Resumo}

As atividades dos postos de gasolina têm em geral o maior potencial de causar danos ao meio ambiente por produtos químicos, gases, solventes, metais e combustíveis em especial. O armazenamento de combustíveis nas valas subterrâneas é o que mais provoca a contaminação do solo. Este estudo tem como objetivo analisar a estrutura de tratamento de efluentes de uma caixa separadora de água e subprodutos petroquímicos de um posto de gasolina, comparar os resultados com a legislação e avaliar seu potencial de reuso no processo. No Brasil, a legislação pertinente à atividade de armazenamento e distribuição de combustível data do ano 1997, com a edição da Resolução do Conselho Nacional do Meio Ambiente (CONAMA) $n^{\circ}$. 237/97, que cita a atividade como sendo sujeita ao licenciamento ambiental e a CONAMA 430/2011 complementa e altera a Resolução n 357/2005 que dispõe sobre as condições e padrões de lançamento de efluentes. No efluente de saída da caixa separadora, notamos que ainda ocorre anomalias, como o excesso de surfactantes e também na DBO, levando em consideração que esses dois parâmetros afetam a qualidade da água para o seu potencial reuso, e podendo causar contaminação no solo e lençol freático. Aconselhamos o uso do filtro com carvão ativado, por ser um método mais viável e que consegue atender as necessidades de devolver esse efluente dentro das normas padronizadas, possibilitando o reuso do efluente em descargas, jardinagem, lavar ambientes, dentre outros.

Palavras-chave: Efluente de caixa separadora; Posto de combustível; Meio Ambiente.

\begin{abstract}
Gas station activities generally have the greatest potential to cause damage to the environment by chemicals, gases, solvents, metals and fuels in particular. The packaging of fuels in underground ditches is what most causes soil contamination. This study aims to analyze an effluent treatment structure from a water separator box and petrochemical by-products from a gas station, compare the results with the legislation and evaluate its potential for reuse in the process. In Brazil, the legislation pertaining to the fuel storage and distribution activity dates from 1997, with the edition of the Resolution of the National Environment Council (CONAMA) $n^{\circ}$. 237/97, which cites the activity as being requested for environmental licensing and CONAMA 430/2011 complements and amends Resolution No. 357/2005, which provides for the conditions and standards for the discharge of effluents. In the effluent leaving the separator box, we note that anomalies still occur, such as the excess of surfactants and also in the BOD, taking into account that these two parameters affect the water quality for its potential reuse, and may cause contamination in the soil and sheet. phreatic. We advise the use of the activated carbon filter, as it is a more viable method and can meet the need to return this effluent within standardized standards, allowing the reuse of effluent in discharges, gardening, washing environments, among others.
\end{abstract}

Keywords: Separating box effluent; Fuel station; Environment. 


\begin{abstract}
Resumen
Las actividades de las estaciones de servicio generalmente tienen el mayor potencial de causar daños al medio ambiente por productos químicos, gases, solventes, metales y combustibles en particular. El almacenamiento de combustible en zanjas subterráneas es lo que más contamina el suelo. Este estudio tiene como objetivo analizar la estructura de tratamiento de efluentes de una caja separadora de agua y subproductos petroquímicos de una gasolinera, comparar los resultados con la legislación y evaluar su potencial de reutilización en el proceso. En Brasil, la legislación relativa a la actividad de almacenamiento y distribución de combustibles data de 1997, con la edición de la Resolución del Consejo Nacional de Medio Ambiente (CONAMA) nº. 237/97, que cita la actividad como sujeta a licenciamiento ambiental y CONAMA 430/2011 complementa y modifica la Resolución No. 357/2005, que establece las condiciones y estándares para la descarga de efluentes. En el efluente que sale de la caja separadora, observamos que aún se producen anomalías, como el exceso de tensioactivos y también en la DBO, teniendo en cuenta que estos dos parámetros afectan la calidad del agua para su potencial reutilización, pudiendo provocar contaminación en el suelo y laminar. freático. Aconsejamos el uso del filtro de carbón activado, por ser un método más viable que puede satisfacer las necesidades de devolver este efluente dentro de estándares estandarizados, permitiendo la reutilización del efluente en vertidos, jardinería, ambientes de lavado, entre otros.
\end{abstract}

Palabras clave: Efluente de la caja separadora; Gasolinera; Medio ambiente.

\title{
1. Introdução
}

A água é um dos nossos bens mais preciosos, devemos zelar sempre pelo seu uso adequado e consciente. A crescente demanda em função do aumento da população e também do desenvolvimento tecnológico acarreta uma escassez desse bem em diversas áreas.

A vida humana é extremamente dependente da água, pois ela proporciona múltiplos usos indispensáveis a nossa sobrevivência, tais como: o consumo humano, o abastecimento industrial, a irrigação, a produção de energia elétrica e as atividades de lazer e recreação, assim como a preservação da vida aquática (Barros et al., 2012).

A população é carente de muitas informações pertinentes sobre a preservação das características estruturais das nascentes, rios e solos.

Para Costa et al. (2012) e Amaro (2009), índices e indicadores ambientais são importantes na estratégia de programas de monitoramento e gestão ambiental por converter uma série de informações através de um único número, um símbolo, uma cor ou descrição verbal de fácil compreensão, possibilitando a tomada de decisões por gestores em várias áreas de atuação.

Um dos índices mais utilizados na área de recursos hídricos é o Índice de Qualidade da Água (IQA), desenvolvido em 1970, pela National Sanitation Foudation (NSF) dos Estados Unidos baseando-se numa pesquisa de opinião junto a especialistas na área (IGAM, 2014).

As indústrias em geral são as principais responsáveis pela contaminação das águas, pois lançam os seus efluentes diretamente nos cursos hídricos sem o devido tratamento ou depositam de forma irregular no solo; podendo essas causar sérios danos ao meio ambiente, contaminando o solo e as águas superficiais e subterrâneas, tornando-as impróprias para o uso e também gerando problemas a saúde e bem-estar humano.

Tornam-se cada vez maiores as problemáticas ambientais, frente a destruição do patrimônio natural o governo vem tomando partido nesta questão, com o intuito de remediar o perigo iminente em que o planeta se encontra.

As atividades dos postos de gasolina têm em geral o maior potencial a causar danos ao meio ambiente por produtos químicos, gases, solventes, metais e combustíveis em especial. O armazenamento de combustíveis nas valas subterrâneas é o que mais provoca a contaminação do solo.

No Brasil, a legislação pertinente à atividade de armazenamento e distribuição de combustível data do ano 1997, com a edição da Resolução do Conselho Nacional do Meio Ambiente (CONAMA) nº 237/97, que cita a atividade como sendo 
sujeita ao licenciamento ambiental e a CONAMA 430/2011 Complementa e altera a Resolução n ${ }^{\circ}$ 357/2005 que dispõe sobre as condições e padrões de lançamento de efluentes.

Os postos de gasolina, também oferecem serviços de lavagem de carro que acarreta na poluição e contaminação, pois resulta em liberação de produtos poluidores que muitas vezes chegam através de canaletas aos coletores de esgoto, podendo causar a obstrução das redes e danos aos equipamentos e instalações de tratamento, tal como podem chegar a contaminar os lençóis freáticos. De acordo com as normas ambientais instalações que oferecem esse tipo de serviço precisam ter instalado recipientes próprios para filtrar e armazenar o óleo utilizado na pulverização dos veículos. Esse procedimento faz a separação da água e do óleo de modo a liberar apenas a água, quando se atinge a capacidade limite do reservatório a empresa especializada deve retirar o produto e dar correto destino a ele, garantindo assim segurança ao meio ambiente.

Em alguns casos apenas esse sistema por si só não é o suficiente, ou se torna falho com o tempo, necessitando de reparo ou até mesmo a sua troca.

O excesso de detergente é um fator de prejuízo de nível estético, provocada pela formação de espumas, além disso exerce efeito tóxico na vida aquática e ainda tem sido considerado um acelerador na eutrofização. Já a DBO é um fator positivo dos ciclos vitais, quando dentro dos padrões, ainda que seja necessário que haja um equilíbrio entre o consumo e a produção de oxigênio no meio, essa relação para que não seja prejudicada não pode haver consumo excessivo, ou seja, excesso de alimento em relação ao volume de água, uma vez que as reservas disponíveis de oxigênio na água são limitadas.

Este estudo tem como objetivo geral avaliar a qualidade do efluente de entrada e saída da caixa separadora de um posto de gasolina e seu potencial de reuso no processo, ou em outra função visando a redução da captação de água potável. Pretende-se, ainda chamar mais atenção para as questões ambientais em face a má utilização dos recursos naturais e da emissão desenfreada de resíduos potencialmente poluidores no meio ambiente, fomentar a adoção de medidas que tenham maior potencial de eliminação de resíduos gerados e que sejam mais eficientes no tratamento deste efluente, para que se devolva ao meio tratado ou que se possa fazer o reuso do mesmo,

Neste trabalho, os resultados obtidos são comparados com os parâmetros previstos na legislação vigente, e através do estudo, indicadas possíveis soluções para o problema abordado, primando pela conscientização ambiental dos empreendedores, e minimizando, assim, a contaminação de cursos d'água, e a emissão de multas.

\section{Metodologia}

O estudo é abordado de modo quali-quantitativo, uma vez que é realizada a análise da água de entrada e saída de um posto de gasolina e avaliado esses dados numéricos na legislação vigente.

Para a realização do presente trabalho, o estudo foi sequenciado nas etapas descritas a seguir (Figura 1): 
Figura 1 - Etapas do estudo.

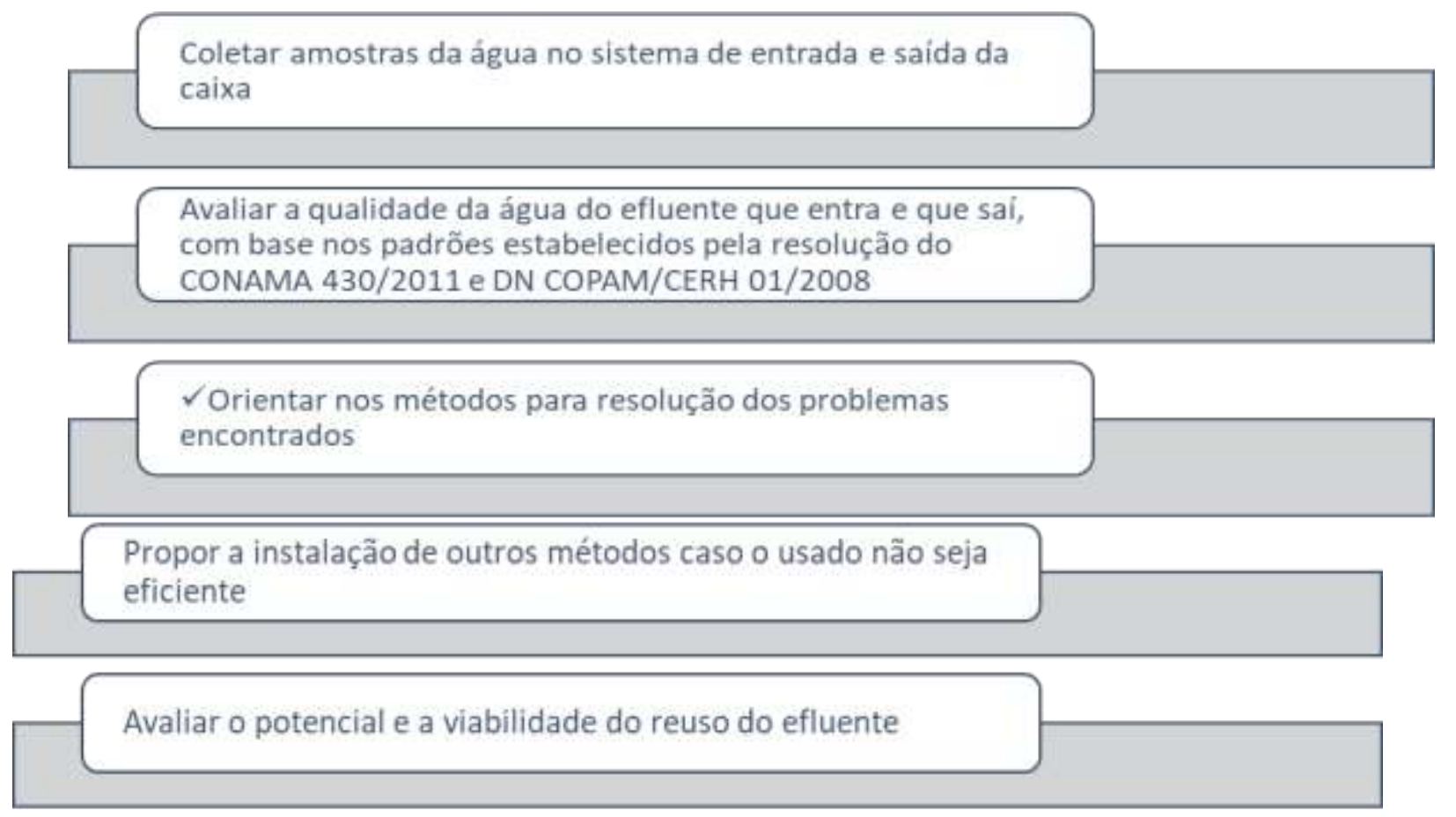

Fonte: Autores.

O presente trabalho foi desenvolvido por meio de análise do efluente realizada em parceria com uma empresa local de João Monlevade-MG.

Os resultados foram comparados com os padrões previsto em lei (CONAMA 430/2011 e DN COPAM/CERH 01/2009 - Lançamento de efluentes).

\section{Materiais e Métodos}

Foram recolhidas as amostras de água, em dois pontos distintos, na entrada e na saída da caixa separadora de água e óleo, as coletas foram feitas dentro do método nº1060 e norma ABNT NBR 9898/1987 - Preservação e técnicas de amostragem de efluentes líquidos e corpos receptores, temperatura da amostra na recepção: 24,2º (graus Celsius) (Quadro 1).

Quadro 1. Preservação e distribuição dos itens de ensaio.

\begin{tabular}{|c|c|c|c|c|}
\hline \multicolumn{5}{|c|}{ Preservação e distribuição dos itens de ensaio (por amostra) } \\
\hline $\begin{array}{c}\text { COD. DA } \\
\text { PRESERVAÇÃO }\end{array}$ & $\begin{array}{c}\text { CODIGO DO } \\
\text { LABORATÓRIO }\end{array}$ & DESCRIÇÃO DA PRESERVAÇÃo & $\begin{array}{c}\text { QUANTIDADE } \\
\text { APROXIMADA }\end{array}$ & RECIPIENTE \\
\hline RP & COL & Refrigeração & $1000 \mathrm{~mL}$ & Frasco Plástico \\
\hline SO & FQ3 & Refrigeração & $1000 \mathrm{~mL}$ & Frasco Plástico \\
\hline RF & FQ4 & Refrigeração sem agitar & $1000 \mathrm{~mL}$ & Frasco Plástico \\
\hline SP & FQ4 & Ácido sulfúrico (Ph<2) & $1000 \mathrm{~mL}$ & Plástico \\
\hline RP & FQ2 & Refrigeração & $1000 \mathrm{~mL}$ & Frasco Plástico \\
\hline SA & FQ2 & Ácido Sulfúrico (PH<2) Boca larga & $1000 \mathrm{~mL}$ & Vidro \\
\hline
\end{tabular}

Fonte: Laboratório local (2018) 
Elencando os parâmetros a ser analisados e avaliados no efluente coletado:

I. SURFACTANTES

II. SÓLIDOS SEDIMENTÁVEIS

III. POTENCIAL HIDROGENIÔNICO -PH

IV. DEMANDA BIOQUIMICA DE OXIGÊNIO - DBO

V. DEMANDA QUIMICA DE OXIGÊNIO - DQO

VI. SÓLIDOS SUSPENSOS TOTAIS

VII. ÓLEOS E GRAXAS TOTAIS

\section{Resultados e Discussão}

Os resultados aqui apresentados são de uma empresa do ramo: Posto de Gasolina, da cidade de João Monlevade - MG no estabelecimento em questão são realizadas as atividades de lavagem de veículos, troca de óleo, filtros e lubrificação, além, é claro, de armazenamento e abastecimento de combustíveis, que são as atividades principais da entidade.

A Resolução CONAMA n n $^{\circ} 57 / 2005$ não estabelece um padrão de lançamento para surfactantes. Esta resolução apenas estabelece o limite máximo permissível de concentração em um corpo hídrico, em função de sua classe, conforme Quadro 2.

Quadro 2. Limite de concentração máxima de surfactantes de acordo com a Resolução CONAMA 357/2005.

\begin{tabular}{|c|c|c|}
\hline & Classe das águas & Limite máximo permitido \\
\hline MBAS & $\begin{array}{l}\text { Limite máximo permitido } \\
\text { Doces, salobras }\end{array}$ & $\begin{array}{l}0,5 \mathrm{mg} / \mathrm{L} \text { LAS (alquil benzeno } \\
\text { sulfonato linear) para águas } \\
\text { doces, e } 0,2 \mathrm{mg} / \mathrm{L} \text { LAS para } \\
\text { águas salobras e salinas }\end{array}$ \\
\hline
\end{tabular}

Fonte: CONAMA (2018)

A análise do efluente deste posto na entrada da caixa separadora de água e óleo (Quadro 3), permite observar discrepâncias no efluente analisado, sendo três valores de parâmetros encontrados fora do limite aceitável: DBO, surfactantes (detergente), sólidos totais suspensos. Esses dados eram previsíveis, visto se tratar de um efluente sem nenhum tipo de tratamento prévio esses fatores, que deverão estar em menor quantidade se comparado com os resultados da análise na saída da caixa.

Os valores encontrados para a entrada e a saída encontram-se nos Quadros 3 e 4 a seguir a seguir: 
Quadro 3. Amostra entrada caixa separadora de água e óleo.

\begin{tabular}{|c|c|c|c|c|c|c|}
\hline \multicolumn{7}{|c|}{ Amostra Entrada Caixa Separadora De Água E Oleo } \\
\hline Ensaio & Resultado & Unidade & Limite Aceitável & LQ & Método & $\begin{array}{c}\text { Data do } \\
\text { ensaio }\end{array}$ \\
\hline pH & 7,34 & {$[\mathrm{H}]+$} & $\begin{array}{c}\text { 5,0 A 9,0 (CNE) OU } \\
\text { 6,0 A 9,0 (CPE) }\end{array}$ & $\begin{array}{c}0,0 \\
1\end{array}$ & $\begin{array}{c}\text { SWEWW 22ND } \\
\text { ed.4500 H+ B }\end{array}$ & $28 / 03 / 2018$ \\
\hline $\begin{array}{c}\text { Sólidos } \\
\text { sedimentáveis }\end{array}$ & $<0,3$ & $\mathrm{~mL} / \mathrm{L}$ & 1 & 0,3 & $\begin{array}{l}\text { SMEWW 22ND } \\
\text { ed } 2540 \mathrm{~F}\end{array}$ & $09 / 04 / 2018$ \\
\hline DBO & 97,6 & $\mathrm{mg} / \mathrm{L} \mathrm{O}_{2}$ & $\begin{array}{c}60 \text { (CPE) OU } \\
\text { REDUÇÃO DE NO } \\
\text { MÍNIMO 75\% APÓS } \\
\text { TRATAMENTO OU } \\
\text { (CNE) REMOÇÃO } \\
\text { MÍNIMA DE 60\% }\end{array}$ & 2 & $\begin{array}{l}\text { SMEWW 22DN } \\
\text { ed } 5210 \mathrm{~B}\end{array}$ & $10 / 04 / 2018$ \\
\hline DQO & 208 & $\mathrm{mg} / \mathrm{L} \mathrm{O}_{2}$ & $\begin{array}{c}180 \text { (CPE) OU } \\
\text { REDUÇÃO DE NO } \\
\text { MÍNIMO 70\% APÓS } \\
\text { TRATAMENTO OU } \\
\text { (CNE) PADRÃO não } \\
\text { fixado }\end{array}$ & 10 & $\begin{array}{l}\text { SMEWW 22ND } \\
\text { ed } 5220 \mathrm{C}\end{array}$ & $10 / 04 / 2018$ \\
\hline Surfactantes & 5,7 & $\mathrm{mg} / \mathrm{L}$ & 2,0 (CPE) & 0,1 & $\begin{array}{l}\text { SMEWW 22ND } \\
\text { ed } 5540 \mathrm{C}\end{array}$ & $16 / 04 / 2018$ \\
\hline $\begin{array}{c}\text { Sólidos } \\
\text { Suspensos } \\
\text { Totais }\end{array}$ & 163 & $\mathrm{mg} / \mathrm{L}$ & $100,0(\mathrm{CPE})$ & 10 & $\begin{array}{c}\text { SMEWW 22ND } \\
\text { ed } 5540 \mathrm{D}\end{array}$ & $10 / 04 / 2018$ \\
\hline $\begin{array}{c}\text { Óleo e Graxas } \\
\text { Totais }\end{array}$ & $>1000$ & $\mathrm{mg} / \mathrm{L}$ & ---------- & 5 & $\begin{array}{l}\text { SMEWW 22ND } \\
\text { ed } 5520 \mathrm{~B}\end{array}$ & $16 / 04 / 2018$ \\
\hline
\end{tabular}

Legenda:

(L1) CONAMA 430:2011 e DN COPAM/CERH 01:2008 - Lançamento de Efluentes.

SM: Stardard Methods for the examination of Water and Wasterwater, 22nd. Edition, 2012.

(CNE) CONAMA430/2011 - Lançamento de Efluentes.

LQ Limite de Quantificação do método de ensaio.

Fonte: Laboratório local (2018).

Para o efluente de saída da caixa separadora, os resultados apontam que ocorrem anomalias referentes ao excesso de surfactantes e também valores alterados de DBO, que refletem diretamente na qualidade da água para o seu potencial reuso, podendo comprometer o futuro reuso desta água, além de causar contaminação no solo e lençol freático. Diante desses dados, uma possível solução para mitigação seria instalar um filtro com carvão ativado. 
Quadro 4. Amostra saída caixa separadora de água e óleo.

\begin{tabular}{|c|c|c|c|c|c|c|}
\hline \multicolumn{7}{|c|}{ Amostra Saída Caixa Separadora De Água E Oleo } \\
\hline Ensaio & Resultado & Unidade & Limite Aceitável & LQ & Método & $\begin{array}{c}\text { Data do } \\
\text { ensaio }\end{array}$ \\
\hline $\mathbf{p H}$ & 7,53 & {$[\mathrm{H}]+$} & $\begin{array}{c}5,0 \text { A 9,0 (CNE) } \\
\text { OU 6,0 A 9,0 (CPE) }\end{array}$ & 0,01 & $\begin{array}{c}\text { SWEWW } \\
\text { 22ND ed.4500 } \\
\text { H+ B }\end{array}$ & $28 / 03 / 2018$ \\
\hline $\begin{array}{c}\text { Sólidos } \\
\text { sedimentáveis }\end{array}$ & $<0,3$ & $\mathrm{~mL} / \mathrm{L}$ & 1 & 0,3 & $\begin{array}{c}\text { SMEWW 22ND } \\
\text { ed } 2540 \mathrm{~F}\end{array}$ & $09 / 04 / 2018$ \\
\hline DBO & 68,4 & $\mathrm{mg} / \mathrm{L} \mathrm{O} 2$ & $\begin{array}{c}60 \text { (CPE) OU } \\
\text { REDUÇÃO DE NO } \\
\text { MÍNIMO } 75 \% \\
\text { APÓS } \\
\text { TRATAMENTO } \\
\text { OU (CNE) } \\
\text { REMOÇÃO } \\
\text { MÍNIMA DE } 60 \%\end{array}$ & 2 & $\begin{array}{c}\text { SMEWW 22DN } \\
\text { ed } 5210 \mathrm{~B}\end{array}$ & $10 / 04 / 2018$ \\
\hline DQO & 5,4 & $\mathrm{mg} / \mathrm{L} \mathrm{O}_{2}$ & $\begin{array}{c}180 \text { (CPE) OU } \\
\text { REDUÇÃO DE NO } \\
\text { MÍNIMO 70\% } \\
\text { APÓS } \\
\text { TRATAMENTO } \\
\text { OU (CNE) } \\
\text { PADRÃO não } \\
\text { fixado }\end{array}$ & 10 & $\begin{array}{c}\text { SMEWW 22ND } \\
\text { ed } 5220 \mathrm{C}\end{array}$ & $10 / 04 / 2018$ \\
\hline Surfactantes & 142 & $\mathrm{mg} / \mathrm{L}$ & $2,0(\mathrm{CPE})$ & 0,1 & $\begin{array}{c}\text { SMEWW 22ND } \\
\text { ed } 5540 \mathrm{C}\end{array}$ & $16 / 04 / 2018$ \\
\hline $\begin{array}{c}\text { Sólidos Suspensos } \\
\text { Totais }\end{array}$ & 35 & $\mathrm{mg} / \mathrm{L}$ & $100,0(\mathrm{CPE})$ & 10 & $\begin{array}{l}\text { SMEWW 22ND } \\
\text { ed } 5540 \text { D }\end{array}$ & $10 / 04 / 2018$ \\
\hline $\begin{array}{c}\text { Óleo e Graxas } \\
\text { Totais }\end{array}$ & 6 & $\mathrm{mg} / \mathrm{L}$ & --------- & 5 & $\begin{array}{c}\text { SMEWW 22ND } \\
\text { ed } 5520 \mathrm{~B}\end{array}$ & $16 / 04 / 2018$ \\
\hline
\end{tabular}

\section{Legenda:}

(L1) CONAMA 430:2011 e DN COPAM/CERH 01:2008 - Lançamento de Efluentes.

SM: Stardard Methods for the examination of Water and Wasterwater, 22nd. Edition, 2012.

(CNE) CONAMA430/2011 - Lançamento de Efluentes.

LQ Limite de Quantificação do método de ensaio.

Fonte: Laboratório local (2018).

Uma alternativa para o reuso do efluente seria emprega-lo no banheiro do posto de gasolina para as finalidades de descarga sanitária e lavagem do chão. 
Machado et al. (2006) afirmam que as indústrias buscam alternativas para a otimização do uso da água e tratamento adequado em relação aos despejos. Uma das formas de se evitar os efeitos danosos desses lançamentos sobre o ambiente consiste na remoção da matéria orgânica através de sistemas de tratamento.

Os estudos realizados por Marta Verônica Buss (Revista de Engenharia Civil IMED, 2(1): 2-10, 2015) indicaram que o único processo que se revelou capaz de produzir um efluente dentro das especificações para ser descartado em um corpo hídrico receptor foi a adsorção/coagulação/floculação. Esse processo, entretanto, mostrou-se ineficaz na remoção de surfactantes, o que reforça que o uso de um filtro de carvão ativado, método menos estudado, mais barato poderia ser mais eficiente no tratamento.

Os detergentes por possuírem moléculas polares e apolares em sua composição, são facilitadores da miscigenação de subprodutos petroquímicos com a água, dificultado a remoção destes e possibilitando a imersão tanto no corpo d'água, quanto nos leitos rochosos, solo e até mesmo na absorção por plantas e animais.

Considerando o efluente impróprio para o reuso e até mesmo para o descarte sem os devidos tratamentos, o ideal seria trocar a caixa coletora por uma mais eficiente, e a acrescer um filtro de carvão ativado. Esse sistema pode também ser feito de maneira mais rústica, intercalando o carvão ativado com uma granulometria mais grosseira e outro com uma granulometria mais fina, uma camada de brita, outra de cascalho e areia.

Tal método além de indicar melhor eficiência, soma a vantagem de ser mais barato se comparado a outros como a coagulação e a flotação, vistos que esses demandam equipamentos mais sofisticados e mais complexos. O aspecto operacional dos filtros é algo simples e envolve baixo custo, podendo ser produzido de maneira rústica, utilizando carvão ativado, com uma granulometria mais grosseira e outro com uma granulometria mais fina, uma camada de brita, outra de cascalho, areia.

\section{Referências}

Amaro, C. A. (2009). Proposta de um índice para avaliação de conformidade da qualidade dos corpos hídricos ao enquadramento (Doctoral dissertation, Universidade de São Paulo).

Barros, J. C. (2012, August). Aplicação do Índice de Qualidade das Águas (IQA-CETESB) no açude Gavião para determinação futura do Índice de Qualidade das Águas Brutas para fins de Abastecimento Público (IAP). In VII CONNEPI-Congresso Norte Nordeste de Pesquisa e Inovação.

Brasil. (2005) Resolução no 357, de 17 de março de 2005. Conselho Nacional do Meio Ambiente (CONAMA). Dispõe sobre a classificação dos corpos de água e diretrizes ambientais para o seu enquadramento, bem como estabelece as condições e padrões de lançamento de efluentes e dá outras providências. Diário Oficial da União, Brasília, DF, 18 mar. 2005. Seção 1, 58-63.

Buss, M. V., Ribeiro, E. F., Schneider, I. A. H., \& dos Santos Menezes, J. C. S. (2015). Tratamento Dos Efluentes De Uma Lavanderia Industrial: Avaliação Da Capacidade De Diferentes Processos De Tratamento. Revista de Engenharia Civil IMED, 2(1), 2-10.

CETESB. Companhia Ambiental do Estado de São Paulo. http://cetesb.sp.gov.br/.

da Costa, A. B., Posselt, E. L., Menezes, C. M., \& Lobo, E. A. (2012). Desenvolvimento e aplicação de índices de qualidade da água. Caderno de Pesquisa, 24(1), 69-77.

Karami, M., \& Zare, A. (2018). Production, characterization and usage of a novel disulfonic acid-functionalized ionic liquid as a highly efficient and dualfunctional catalyst for the synthesis of 1, 8-dioxo-9, 10-diaryl-decahydroacridines. Química Nova, 41(7), 762-769.

IGAM - Instituto Mineiro De Gestão Das Águas. Qualidade das Águas Superficiais de Minas Gerais em 2013. Resumo Executivo. Belo Horizonte: IGAM, 2014. http://pnqa.ana.gov.br/indicadores-indice-aguas.aspx.

Montano, J. Principais parâmetros de análise de efluentes para lançamento em corpos d'água. < http://ambientesst.com.br/principais-parametros-de-analise-deefluentes/

Moreira, M. Postos de combustível lideram a lista dos que mais poluem o solo urbano em SP. http://agenciabrasil.ebc.com.br/geral/noticia/2014-06/postos-decombustivel-lideram-lista-dos-que-mais-poluem-o-solo-urbano-em-sp

Machado, G. B., Rosa, L. C. L., Fiorini, M. P. (2006). Avaliação da eficiência do processo da ETE do tipo lodos ativados de uma indústria química de JacareíSP. X Encontro Latino Americano de Iniciação Científica e VI Encontro Latino Americano de Pós-Graduação-Universidade do Vale do Paraíba. Rev Univap, 13, 140-142.

NATURALTEC. Filtração. http://www.naturaltec.com.br/filtracao-teoria/ 